Tarih Öğretimi Bağlamında İnternete Özgü Epistemik Gerekçelendirme Ölçeğinin Türk Kültürüne Uyarlaması

Adaptation of Internet-Specific Epistemic Justification Inventory to Turkish Culture in the Context of History Teaching

\title{
Servet ÜZTEMUR
}

Gaziantep Üniversitesi, Nizip Eğitim Fakültesi, E-posta: servetuztemur@gmail.com orcid.org/0000-0002-1580-9123

\section{Erkan DiNÇ}

Uşak Üniversitesi, Eğitim Fakültesi, E-posta: erkandinc@gmail.com

orcid.org/0000-0002-0953-3351

\section{Article Info}

\begin{tabular}{|c|c|}
\hline Article Type & Research \& Theoretical \\
\hline Received & 01.02 .2020 \\
\hline Accepted & 25.03 .2020 \\
\hline $\mathrm{DOI}$ & 10.17497/tuhed.683267 \\
\hline $\begin{array}{c}\text { Corresponding } \\
\text { Author }\end{array}$ & Servet ÜZTEMUR \\
\hline Cite & $\begin{array}{l}\text { Üztemur, S., Dinç, E. (2020). Tarih öğretimi bağlamında internete } \\
\text { özgü epistemik gerekçelendirme ölçeğinin Türk kültürüne } \\
\text { uyarlaması. Turkish History Education Journal, 9(1), ss. 152-169. } \\
\text { DOI: } 10.17497 / \text { tuhed.683267 }\end{array}$ \\
\hline
\end{tabular}


Öz: Bu araştırmanın amacı “internete Özgü Epistemik Gerekçelendirme Ölçeği”ni Türk kültürüne uyarlayarak geçerlik ve güvenilirlik çalışmalarını yapmaktır. İnternetten edinilen bilgilerin kapsamının çok geniş olması nedeniyle, bu araştırmada konu alanı internet üzerinden erişilen tarihsel bilgiler ile sınırlandırılmıştır. Çalışma Uşak ve Necmettin Erbakan Üniversitelerinde 20192020 öğretim yılında öğrenimine devam eden rastgele seçilmiş 192 sosyal bilgiler öğretmen adayıyla gerçekleştirilmiştir. Doğrulayıcı faktör analizi ve alfa iç tutarlılık hesaplamaları sonuçları, 12 maddelik ölçeğin üç boyutlu (kişisel gerekçelendirme, çoklu kaynaklar tarafından gerekçelendirme ve otorite tarafından gerekçelendirme) orijinal yapısının Türk kültüründe geçerli ve güvenilir olduğunu ortaya koymuştur. Araştırma sonuçları; internetin bilgi kaynağı olarak kullanıldığı post-truth zamanlarda, gençlerin web ortamında karşılaştıkları bilgi iddialarının doğruluğunu sınama sürecinde benimsedikleri epistemik gerekçelendirme stratejileri ile tarihsel muhakeme ve tarihsel bağlamsallaştırma becerileri bağlamında tartışılımışır.

Anahtar Kelimeler: Tarih Öğretimi, Epistemik Gerekçelendirme, Post-truth Zamanlar, Sosyal Bilgiler, Tarihsel Bağlamsallaştırma

\begin{abstract}
The aim of this research is to adapt the "Internet-Specific Epistemic Justification Inventory" to Turkish culture and conduct validity and reliability tests. Due to the wide scope of knowledge obtained from the internet, the subject focus of this research is limited to historical knowledge accessed via the internet. The study was conducted with the participation of 192 randomly selected prospective social studies teachers continuing their education at Uşak and Necmettin Erbakan Universities in the 2019-2020 academic year. The results of confirmatory factor analysis and alpha internal consistency calculations revealed that the three-dimensional (personal justification, justification by multiple sources and justification by authority) structure of the 12-item inventory is valid and reliable in Turkish culture. The research results were discussed in the context of epistemic justification strategies and historical reasoning and historical contextualization skills adopted by young people in the process of testing the accuracy of knowledge claims they encounter in the web in post-truth times when the internet is used as a source of knowledge.
\end{abstract}

Keywords: History Teaching, Epistemic Justification, Post-truth Times, Social Studies, Historical Contextualization

\title{
Extended Summary
}

\section{Purpose}

In today's technology age, the internet has become the primary source of knowledge because it is very easy and fast in accessing knowledge. As a result, various knowledge is shared on the internet. Due to the lack of control mechanisms in the internet environment, knowledge is readily available on all kinds of websites, and this leads to knowledge confusion and distortions (Braten, Brandmo \& Kammerer, 2018). In today's post-truth times, due to the fact that objective facts are less important to public opinion than individual opinions, it is observed that tailored knowledge appropriate to the political and ethnic views of individuals rather than actual knowledge is available in the internet environment (Simsek \& Yali, 2019). Individuals need to justify the objectivity, reliability, and accuracy of the knowledge they access on the internet in such a climate of confusion and uncertainty (Braten et al., 2018). 
As a reflection of the use of the internet as the main source of knowledge today, the internet itself is also the place where historical knowledge is most shared and discussed. The Internet also provides easier access to many materials and archival resources that will be useful in history courses (Pearcy, 2014). This occasion has its good sides as well as the bad ones, such as the deliberate mistranslation, distortion, and anachronism of historical knowledge. It was particularly emphasized in related research that young people are unable to evaluate online sources of knowledge critically (Cho, Han \& Kucan, 2018; Wineburg, 1991). It has been expressed by many researchers that the existing practices in higher education institutions are largely insufficient in the development of reasoning and justification skills of university students and that these skills are weak during the university education (Kuhn et al., 2000; Lee et al., 2019; Soong et al., 2012). Based on this point, the purpose of this research is to conduct the validity and reliability studies and adaptation to Turkish culture of the "InternetSpecific Epistemic Justification Inventory" that was developed by Braten et al. (2018) to determine how and in what ways prospective social studies teachers justify the accuracy of the historical knowledge sources they encountered on the internet.

\section{Method}

This study is conducted with a cross-sectional survey model. The study group of the research consists of 192 prospective social studies teachers (66.1\% female, $33.9 \%$ male) studying at Uşak and Necmettin Erbakan Universities in the 2019-2020 academic year. A confirmatory factor analysis (CFA) was conducted to determine the degree to which the inventory was compatible with Turkish culture and also to analyze its structural validity.

\section{Results}

The DFA results showed that the fit indices of the inventory were at excellent levels. The Turkish version of the inventory was found to be compatible with the original structure. Alpha internal consistency coefficients were found as .70 for the personal justification dimension, as .83 for the justification by multiple sources dimension, and as .81 for the justification by authority dimension. No correlation greater than .80 was observed between the sub-dimensions of the inventory. Based on these findings, it can be interpreted that each sub-dimension represents different structures and that there is no problem of multiple correlations between the sub-dimensions of the inventory.

\section{Discussion and Conclusion}

In this study, the adaptation to Turkish culture and validity and reliability tests of the "Internet-Specific Epistemic Justification Inventory" developed by Braten et al. (2018) were performed. The results of the research indicate that the inventory developed within the scope of "Modeling Epistemic and Ontological Cognition" (Greene et al., 2008) is compatible with Turkish culture. As a result of the CFA conducted in accordance with the validity tests, it was found out that the original structure of the inventory consisting of 12 items and three subdimensions did not change in the Turkish version and that the fit indices were acceptable. On the other hand, in line with reliability tests, the alpha internal consistency coefficients of the sub-dimensions were found to be high. Based on all these results, it was concluded that the 
inventory developed to determine how and in what ways prospective social studies teachers justify historical knowledge claims on the internet is valid and reliable.

The internet is the most used resource of Generation $Z$ in their individual learning process. It is obvious that this source of knowledge should be used with care given the reasons such as the fact that the knowledge accessed on the Internet is too much to be controlled and that the content that anyone wishes is made available in a very convenient way (Aşkar \& Mazman, 2013). Therefore, the ability of young people to make the right decisions on issues such as the reliability, quality, objectivity, and suitability of the knowledge accessed on the internet to the relevant subject area should be developed further (Çelik, 2019; Kammerer, Amann \& Gerjets, 2015). When the relevant literature is reviewed, it is seen that young people have limited skills to critically evaluate the resources they access on the internet (Chiu, Tsai \& Liang, 2015; Cho et al., 2018; Tsai, 2009). When the results of the study, which determined how and in what ways young people interpret the knowledge they access on the internet, it is seen that internet-specific epistemological beliefs (Braten et al., 2018; Kammerer et al., 2015; Kammerer, Braten, Gerjets \& Stromso, 2013; Mason, Boldrin \& Ariasi, 2010; Whitmire, 2004) are a significant determinant (Braten et al., 2018).

The articulation of internet-specific epistemic justification beliefs and historical reasoning and historical contextualization skills in one pot is important for the more accurate and appropriate use of the Internet, the current knowledge source, in the process of structuring historical knowledge. Many history educators agree that the students should be guided by the historians' practices in the process of translating the source into evidence on how and in what ways they can reason to read and make sense of historical sources of knowledge/claims. In the process of turning claims of historical knowledge into evidence, historians focus on the harmony between them by comparing many sources with one another. This reading process requires expertise. For historians, having more than one source is an opportunity to compare different perspectives and establish a cause-and-effect connection (Gestsdóttir, van Boxtel \& van Drie, 2018; Monte-Sano, 2011; van Drie \& van Boxtel, 2008). The comparison of many different sources and reaching a decision is similar to that of justification by multiple sources in the process of translating sources into evidence. Accordingly, based on the current research results, a framework has been proposed to establish meaningful relationships between internet-specific epistemic justification skills and historical contextualization skills in the context of history teaching.

\section{Giriş}

Günümüz teknoloji çağında bilgiye ulaşmada çok kolay ve hızlı olması nedeniyle internet birincil bilgi kaynağı haline gelmiştir. Bu durumun bir sonucu olarak internet üzerinde sayısız bilgi paylaşımı yapılmaktadır. Internet ortamında kontrol mekanizmalarının olmamasından dolayı her türlü sitede çeşitli bilgiler çok rahat yer almakta ve bu durum bilgi karmaşasına ve çarpıtmalara yol açmaktadır (Braten, Brandmo \& Kammerer, 2018). Günümüz 
post-truth (gerçeklik ötesi) zamanlarda nesnel olguların kamuoyu oluşturmada bireysel görüşlerden daha az önemsenmesinden dolayı internet ortamında gerçek bilgiden ziyade kişilerin siyasi, politik, etnik vb. görüşlerine uygun ısmarlama bilgilerin çoğunlukta olduğu görülmektedir (Şimşek ve Yalı, 2019). Böylesi bir karmaşa ve belirsizlik ortamında bireylerin internette eriştikleri bilgilerin nesnelliği, güvenilirliği ve doğruluğunu gerekçelendirmeleri (haklılandırma/doğrulama) gerekir (Braten vd., 2018). İngilizcede justification olarak kullanılan gerekçelendirme kavramı felsefede bilgi felsefesinin (epistemoloji) özünü oluşturmaktadır (Chinn, Buckland ve Samarapungavan, 2011). Epistemik gerekçelendirme, kişilerin yaşamları boyunca yüzleştikleri bilgiye yönelik iddiaları (sav) ve aynı zamanda kendi bireysel inançlarını nasıl ve ne şekilde doğruladıkları veya haklılandırdıkları ile ilgilenir (Greene, Azevedo ve Tourney-Purta, 2008; Hofer, 2004). Epistemik gerekçelendirme araştırmacıları, bireylere kişisel görüşlerine göre bir bilginin doğru ve/ya gerçek olabilme ölçütlerinin neler olduğuyla ilgilenir. Buna göre kişiler bir bilginin doğruluğunu gözlem, uzmanlar (otoriteler) ya da kendi mantıksal çerçevelerini doğru addederek gerekçelendirdikleri gibi; kanıtları ve uzman görüşlerini araştırıp mantıksal muhakemeden geçirip değerlendirerek otoritelerin kanaatlerini bütünleştirme yoluyla da gerekçelendirebilirler (Hofer, 2004).

Bireylerin günlük yaşamlarında bilgiyi nasıl ve ne şekilde gerekçelendirdiklerini açıklamak amacıyla Greene ve diğerleri (2008) tarafından "Epistemik ve Ontolojik Biliş Modeli" geliştirilmiştir. Model, ortaokuldan lisansüstüne kadar geniş bir katılımcı kitlesi üzerinde farklı alanlarda (matematik ve tarih) ampirik verilerle desteklenmiş ve daha sonraki çalışmalarla sağlam temellere oturtulmuştur (Ferguson, Braten ve Strøms $\varnothing$, 2012; Greene, Tourney-Purta ve Azevedo, 2010; Dinç ve Üztemur, 2019). Modelin ontolojik kısmı bu araştırmanın kapsamı dışındadır. Modelin epistemik kısmında bireylerin günlük yaşamda karşılaştıkları bilgi iddialarını kişisel gerekçelendirme (personal justification) ve otorite tarafından gerekçelendirme (justification by authority) adı altında iki şekilde gerekçelendirdikleri vurgulanmıştır (Greene vd., 2010). Kişisel gerekçelendirme boyutunda kişiler bilgi iddialarını kendi deneyim, görüş ve mantıksal kavrayışları doğrultusunda gerekçelendirerek başkalarının fikirlerini çok fazla önemsememektedirler. Otoriteler tarafından gerekçelendirme boyutunu benimsemiş bireyler; bilgi iddialarının ve kaynaklarının doğruluğunu sınarken ilgili alandaki saygın bir dış kaynak (bilimsel makale, arşivler vb.) ya da alanında yetkin uzmanlar (profesörler, bilim insanları vb.) aracılığıyla gerekçelendirme yaparlar (Greene vd., 2008). Ferguson ve diğerleri (2012) modele çoklu kaynaklar tarafından gerekçelendirme (justification by multiple sources) adını verdikleri üçüncü bir boyut eklemişlerdir. Bu boyutu benimsemiş bireyler, farklı bilgi kaynakları arasında mukayese etme, çapraz kontrol ve doğrulama yoluyla kaynakların tutarlılığını sınayıp gerekçelendirmektedir. Çoklu kaynaklar tarafından gerekçelendirme boyutu ilgili alanyazında; tam ve net cevabı olmayan konularda farklı yönde bilgi veren belgelerden anlam çıkararak tartışmalı konuların doğruluğunu mantıksal ve tutarlı bir bakış açısıyla değerlendiren başarılı ve yetkin öğrencileri betimlemek amacıyla kullanılmıştır (Ferguson ve Braten, 2013; Ferguson, Braten, Strømsø ve Anmarkrud, 2013).

Ampirik araştırma sonuçları epistemik gerekçelendirmenin karar verme (Köymen vd., 2014), sosyalleşme (Nagel, 2015), çoklu metinlerden anlam çıkarma (Bråten, Ferguson, Strømsø ve Anmarkrud, 2013), tartışmalara katılma istekliliği (Lee vd., 2019) ve eleştirel düşünme (Braten vd., 2018) becerileriyle ilişkili olduğunu ortaya koymuştur. ilgili araştırma 
sonuçları, çoklu kaynaklar tarafından gerekçelendirme boyutunun öğrencilerin içsel motivasyonu ve performanslarıyla pozitif yönde, kişisel gerekçelendirme boyutunun ise tam tersi yönde bir ilişki içerisinde olduğunu vurgulamışlardır. Ayrıca kişisel gerekçelendirme boyutunu benimseyen öğrencilerin bir bilgiyi gerekçelendirirken ön bilgi ve muhakeme becerilerini etkin biçimde kullanmaktan ziyade sağlam temellere dayanmayan kişisel görüş ve duygularıyla hareket ettiği rapor edilmiştir (Braten vd., 2018). Otorite tarafından gerekçelendirme boyutunun öğrencilerin başarılarıyla pek bir ilgisinin olmadığını belirten çalışmaların (Brandmo ve Bråten, 2018; Bråten vd., 2013) yanı sıra, -çok boyutlu epistemik inanç modellerinde (Hofer ve Pintrich, 1997; Schommer, 1990) gelişmemiş (naif) bir epistemik inanca karşılık geldiği yönündeki kavramsallaştırmaların aksine- öğrencilerin başarıları ile pozitif yönde ilişkili olduğunu belirten çalışmalar (Braten vd., 2008; Braten vd., 2014) da alanyazında yer almaktadır.

İlgili alanyazın incelendiğinde internete özgü epistemolojik inançların belirlenmesi amacıyla Braten ve diğerleri (2005) tarafından bilginin kaynağı, kesinliği, basitliği ve gerekçelendirilmesi boyutlarını içeren "İnternet-Odaklı Epistemolojik İnanç Ölçeği" geliştirildiği görülmektedir. Bu ölçekte internete özgü epistemik inançlar genel olarak ele alınmış ve konu alanına özgü epistemik inançlar göz ardı edilmiştir. Bireylerin bir bilginin doğruluğunu gerekçelendirme davranışları, konu alanının doğasından çok etkilenmektedir (Hofer, 2006). Örneğin tıp alanında internette araştırma yapan birisinin otoritelere inanma eğilimi çok yüksektir. Bu durum sosyal bilimler için çok da kolay olmamaktadır. Buna ek olarak ölçekte (Braten vd., 2005) yer alan gerekçelendirme boyutu tek bir yapı olarak ele alınmıştır. Güncel kavramsallaştırmalar (Chinn vd., 2011; Ferguson vd., 2012; Greene vd., 2008), gerekçelendirmenin üç farklı (kişisel, otorite ve çoklu kaynaklar) şekilde gerçekleştiğini vurgulamışlardır. Bu noktadan hareketle bireylerin internet ortamında karşılaştıkları bilgi iddialarını nasıl ve ne şekilde gerekçelendirdiklerini ortaya koymak amacıyla Braten ve diğerleri (2018) kişisel gerekçelendirme, otorite tarafından gerekçelendirme ve çoklu kaynaklar tarafından gerekçelendirme boyutlarını içeren "Internete Özgü Epistemik Gerekçelendirme Ölçeği” geliştirilmiştir. Öğretmen adayları üzerinde uygulanan ölçeğin geçerlik ve güvenilirlik çalışmaları neticesinde gerekçelendirmenin her boyutundan dörder maddenin yer aldığı 12 maddelik ölçeğe son hali verilmiştir. Konu alanı olarak eğitim bilimleri seçilmiştir. Yazarlar ölçeğin her konu alanına uyarlanabileceğini belirtmişlerdir (Braten vd., 2018).

Günümüzde başat bilgi kaynağı olarak internetin kullanılmasının bir yansıması olarak tarihsel bilginin en çok paylaşıldığı ve tartışıldığı yer de yine internetin kendisidir. İnternet sayesinde tarih derslerinde işe yarayacak pek çok materyal ve arşiv kaynağına daha kolay erişim sağlanmaktadır (Pearcy, 2014). Bu durumun iyi yanları olduğu gibi tarihsel bilginin bilerek yanlış aktarılması, çarpıtılması ve anakronizm gibi kötü yanları da bulunmaktadır. Özellikle gençlerin çevrimiçi bilgi kaynaklarını eleştirel bir gözle değerlendiremedikleri ilgili araştırmalarda vurgulanmıştır (Cho, Han ve Kucan, 2018; Wineburg, 1991). Üniversite öğrencilerinin gerekçelendirme ve muhakeme becerilerinin geliştirilmesinde yükseköğretim kurumlarındaki mevcut uygulamaların büyük ölçüde yetersiz olduğu ve öğrencilerin üniversite öğrenimi boyunca bu becerilerinin zayıf kaldığı pek çok araştırmacı tarafından dile getirilmiştir (Kuhn vd., 2000; Lee vd., 2019; Soong vd., 2012). Bu noktadan hareketle bu araştırmanın amacı; sosyal bilgiler öğretmen adaylarının internette başvurdukları tarihsel bilgi kaynaklarının 
doğruluğunu nasıl ve ne şekilde gerekçelendirdiklerini tespit etmek amacıyla Braten ve diğerleri (2018) tarafından geliştirilen “İnternete Özgü Epistemik Gerekçelendirme Ölçeği”nin Türk kültürüne uyarlama, geçerlik ve güvenilirlik çalışmalarını yapmaktır.

\section{Yöntem}

\section{Araştırmanın Deseni}

Bu çalışma, kesitsel tarama modeliyle gerçekleştirilmiştir. Örneklemin çok büyük ve pek çok farklı nitelikten meydana geldiği kesitsel çalışmalarda araştırılacak değişkenler bir kerede ölçülür (Fraenkel vd., 2012).

\section{Çalışma Grubu}

Araştırmanın çalışma grubunu 2019-2020 öğretim yılında Uşak ve Necmettin Erbakan Üniversitesi bünyesinde öğrenim gören kolay ulaşılabilir durum örneklemesi yoluyla seçilmiş 192 sosyal bilgiler öğretmen adayı (\%66,1 kadın, \%33,9 erkek) oluşturmaktadır. Çalışma grubunun $\% 21,9^{\prime}$ u birinci sınıfta, $\% 28,6^{\prime}$ sı ikinci sınıfta, $\% 35,9^{\prime}$ u üçüncü sınıfta ve $\% 13,5^{\prime} i$ dördüncü sınıfta yer almaktadır. Araştırma kapsamında uygulama yapabilmek için Uşak Üniversitesi Etik Kurulundan 10.03.2020 tarih ve E.9713 sayılı onay belgesi alınmıştır.

\section{Veri Toplama Araçları}

Braten ve diğerleri (2018) tarafından üniversite öğrencilerinin internete özgü epistemik gerekçelendirme anlayışlarını ölçmek amacıyla “internete Özgü Epistemik Gerekçelendirme Ölçeği" (iÖEGÖ) geliştirilmiştir. Epistemik ve Ontolojik Biliş Modeli (Greene vd., 2008) doğrultusunda hazırlanan maddelere doğrulayıcı faktör analizi (DFA) yapılmıştır. DFA sonucunda her biri dört maddeden oluşan üç alt boyut ortaya çıkmıştır: kişisel gerekçelendirme $(\alpha=.84)$, otorite tarafından gerekçelendirme $(\alpha=.92)$ ve çoklu kaynaklar tarafından gerekçelendirme $(\alpha=.92)$. Ölçek kesinlikle katılmıyorum (1) ile tamamen katılıyorum (10) ifadeleri arasında değişen 10'lu likert tipinde yapılandırılmıştır. Her bir boyuttan alınan yüksek puanlar o boyutun daha çok benimsendiği anlamını taşımaktadır. Orijinal ölçeği Türkçe'ye uyarlamak için ölçek yazarlarından izin alınmıştır.

\section{İşlem}

Bu bölümde iÖEGÖ’yü Türk kültürüne uyarlamak için yazarlardan izin alınmasına müteakip Hambleton ve Patsula (1999) tarafından önerilen ölçek uyarlama aşamaları göz önünde bulundurularak i) ölçeğin dil geçerliliği çalışmalarının yapılması, ii) Türkçe sürümünün uygulanması ve iii) verilerin analizi işlemleri sırasıyla yapılmıştır.

Ölçek ilk aşamada yazarlarca Türk diline çevrilmiştir. Ölçeğin hem İngilizce hem de Türkçe sürümlerini kapsayan uzman çeviri değerlendirme formları hazırlanıp üçer Türkçe ve İngilizce dil uzmanına gönderilmiş ve fikirleri alınmıştır. Dil uzmanlarından gelen düzeltmeleri takiben ölçeğin Türkçe sürümüne nihai şekli verilmiştir. Ölçeğin Türkçe nihai formu, farklı bir dil uzmanına İngilizceye çevirtilmiş ve ölçeğin İngilizce orijinal sürümüyle mukayese edilmiştir. $\mathrm{Bu}$ işlemler neticesinde ölçeğin nihai Türkçe formu oluşturulmuştur. Ölçeğin tarih eğitimi 
bağlamında uygulanacağından hareketle iki tarih eğitimcisine ölçek inceletilerek fikirleri alınmıştır. Çalışma grubunun haricinde beş sosyal bilgiler öğretmen adayına ölçek doldurtulmuş ve maddelerde anlamadıkları yer olup olmadığı hakkında bilgi alınmıştır. Onlu likert tipi ölçeklerin Türkiye'de pek fazla kullanılmaması (Tavşancıl, 2019; Tezbaşaran, 2008) nedeniyle ölçek beşli likert ( $1=$ kesinlikle katılmıyorum, 5= tamamen katılıyorum) türünde yapılandırılmıştır. Ölçeğin bu son hali 192 sosyal bilgiler öğretmen adayına uygulanmıştır.

Ölçek uyarlama sürecinin son aşamasında veri setinin normallik testleri yapılarak maddelerin basıklık ve çarpıklık değerlerinin -2 ile +2 aralığında olduğu görülmüştür. Bu sonuçlar doğrultusunda verilerin normal dağıldığı söylenebilir (Trochim ve Donnelly, 2006). Analizler SPSS ve AMOS programlarıyla yapılmıştır. Ölçeğin Türk kültürüne ne derecede uyum sağladığını tespit etmek ve aynı zamanda yapısal geçerliğini analizleri için DFA yapılmıştır. Kuramsal açıdan desteklenmiş olan bir yapının Türk kültüründe de doğrulanıp doğrulanmadığını sınamak amacıyla ölçeğe direkt DFA yapılmıştır. Bu sayede hangi boyutta yer alacağı kuramsal açıdan belli olan maddelerin başka boyutlar altında birleşmesinin önüne geçilmiştir. Ölçek uyarlama çalışmalarında, daha önceki çalışmalarla sağlam temellere oturtulmuş halihazırdaki kuramsal modelin, ölçeğin çevrileceği kültürel yapıya uyum sağlayıp sağlamadığının ilk önce DFA ile sınanması gerektiği, bu analiz sonrasında kuramsal model veri setiyle uyum sağlamadığı takdirde açımlayıcı faktör analizi (AFA) yapılması gerektiği alanyazında vurgulanmıştır (Çokluk vd., 2014; Doğan vd., 2017). Orijinal ölçeği geliştiren yazarlar (Braten vd., 2018) da kuramsal temeller doğrultusunda ölçeğe direkt DFA yapmışlardır. DFA sonrasında elde edilen modelin veri setiyle uyum sağlayıp sağlamadığını denetlemek için düzeltilmiş iyilik uyum indeksi (AGFI), ki-karenin serbestlik derecesine bölümü $(\chi 2 / s d)$, yaklaşık hataların ortalama karekökü (RMSEA), artırmalı uyum indeksi (IFI), genel uyum indeksi (GFI) ve karşılaştırmalı uyum indeksi (CFI) değerleri ölçüt alınmıştır (Kline, 2011). Uyum indekslerine ait kıstas değer aralıkları Tablo 2'de gösterilmiştir. Güvenilirlik için Alfa iç tutarlılık katsayısı hesaplanmıştır.

\section{Bulgular}

\section{Geçerlik Çalışmalarına Yönelik Bulgular}

Orijinal ölçeğin Türk kültürüne uyum düzeyini belirlemek ve aynı zamanda ölçeğin yapısal geçerliğini tespit etmek amacıyla yapılan DFA sonuçları Şekil 1'de gösterilmiştir.

Şekil 1'de görüleceği üzere aynı boyut altında yer alan maddeler için önerilen modifikasyonlar yapılmış ve Tablo 1'de bu modifikasyonlar sonrasında oluşan uyum değerleri verilmiştir.

Tablo 1'deki veriler doğrultusunda modifikasyonsuz modelin uyum indeksleri incelendiğinde RMSEA, GFI ve AGFI değerlerinin kabul edilebilir seviyesinin altında yer aldığı görülmüştür. Önerilen modifikasyon indeksleri doğrultusunda öncelikle 1 ve 4 numaralı maddeler arasında hata ilişkilendirmesi yapılmıştır. Bu işlemin akabinde AMOS programı tekrardan çalıştırımıştır. Ortaya çıkan yeni modeli, bir öncekiyle mukayese edebilmek için ki- 
kare fark testi $(\chi 2$ difference test) yapılmıştır (Tabachnick ve Fidell, 2013). Ki-kare fark testi sonucunda, modifikasyon işleminin istatistiksel açıdan modeli daha uyumlu hale getirdiği görülmüştür [ $\chi 2(1, N=192)=12.36, p<.05]$. Bu işlem sonrasında $\mathrm{GFI}$, AGFI ve RMSEA değerlerinin halen kabul edilebilir seviyenin altında olduğu görülmüştür. Bu nedenle 6 ile 12 numaralı maddeleri arasında hata ilişkilendirmesi yapılmış ve ki kare fark testi ile yeni modelin eski modelden anlamlı bir şekilde farklılaşıp farklılaşmadığı kontrol edilmiştir [ $\chi 2 \quad(1, N=192)$ $=24.91 p<.05]$. Bu işlem sonrasında modifikasyon işleminin istatistiksel açıdan modeli daha uyumlu hale getirdiğinin yanı sıra tüm uyum değerlerinin kabul edilebilir ve mükemmel düzeyde olduğu görülmüştür. Nihai modelin yeterliliğini belirlemek için başvurulan uyum indekslerine ait kıstas değerler ve modele ait uyum değerleri Tablo 2' de verilmiştir.

Şekil 1. Modelin Standardize Edilmiş Değerleri

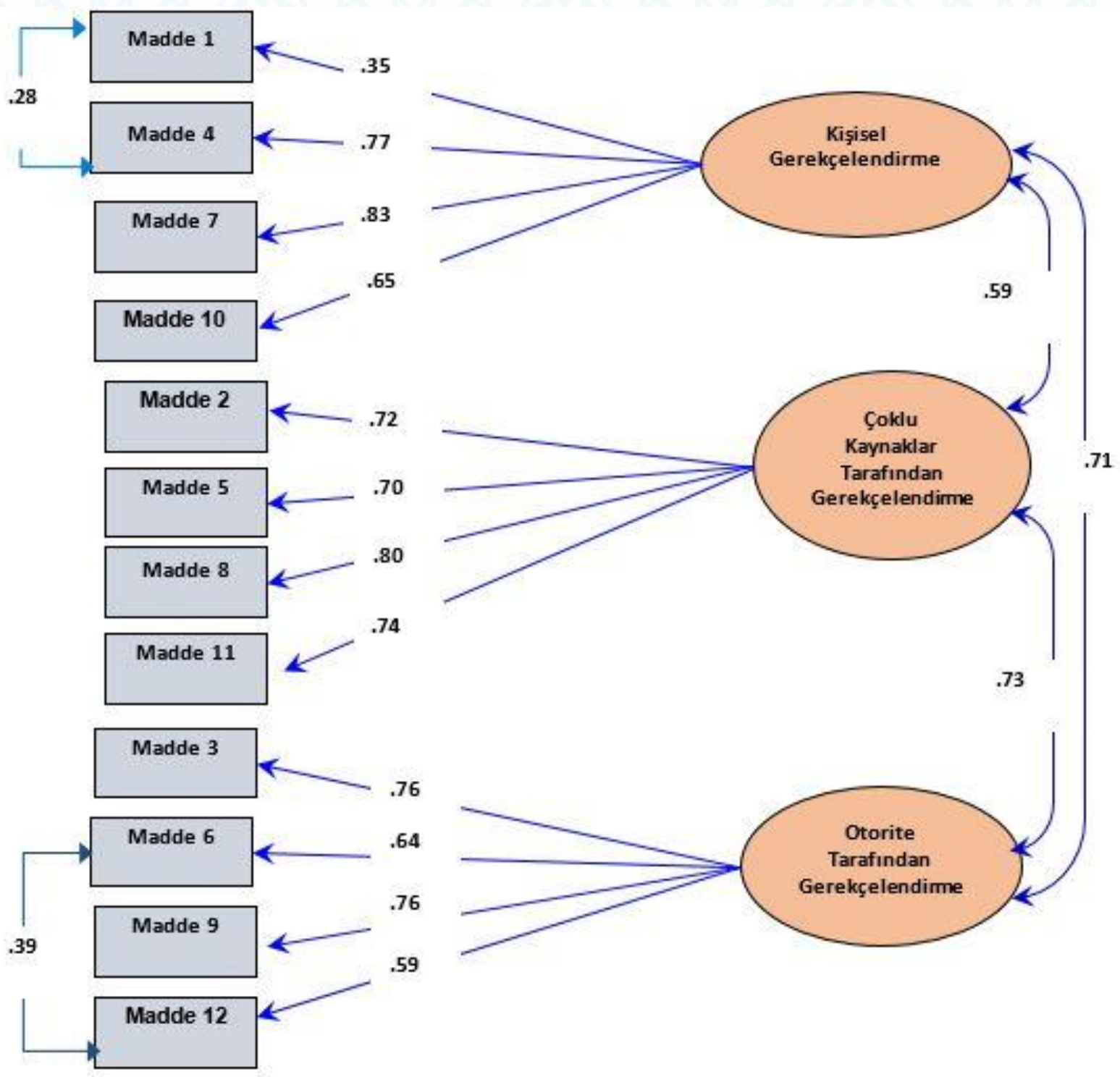


Tablo 1

DFA Modeline Yönelik Uyum İndeksi Değerleri

\begin{tabular}{|c|c|c|c|c|c|c|c|c|c|}
\hline Model & & $x^{2}$ & df & $\chi 2 / d f$ & IFI & GFI & AGFI & CFI & RMSEA \\
\hline Modifikasyonsuz model & & 136.460 & 51 & 2.676 & .924 & .887 & .827 & .923 & .094 \\
\hline $\begin{array}{l}\text { Madde } 1 \text { ile madde } \\
\text { arasında modifikasyon }\end{array}$ & 4 & 124.091 & 50 & 2.482 & .934 & .899 & .842 & .933 & .088 \\
\hline $\begin{array}{l}\text { Madde } 6 \text { ile madde } \\
\text { arasında modifikasyon }\end{array}$ & 12 & 99.172 & 49 & 2.024 & .955 & .914 & .863 & .955 & .073 \\
\hline
\end{tabular}

Tablo 2

Uyum İndekslerine Ait Değer Aralıkları* ve Modelin Uyum Değerleri (N: 192)

\begin{tabular}{lllcl}
\hline $\begin{array}{l}\text { Uyum } \\
\text { Indeksleri }\end{array}$ & $\begin{array}{c}\text { Mükemmel Uyum } \\
\text { Ölçütleri }\end{array}$ & $\begin{array}{c}\text { Kabul Edilebilir } \\
\text { Uyum Ölçütleri }\end{array}$ & $\begin{array}{c}\text { Modelin } \\
\text { Uyum } \\
\text { indeksleri }\end{array}$ & \multicolumn{1}{c}{ Karar } \\
\hline$\chi 2 / \mathrm{df}$ & $0 \leq \mathrm{X} / \mathrm{df} \leq 2$ & $2 \leq \chi 2 / \mathrm{df} \leq 5$ & 2.024 & Kabul Edilebilir Uyum \\
$\mathrm{RMSEA}$ & $.00 \leq \mathrm{RMSEA} \leq .05$ & $.05 \leq \mathrm{RMSEA} \leq .08$ & .073 & Kabul Edilebilir Uyum \\
$\mathrm{CFI}$ & $.95 \leq \mathrm{CFI} \leq 1.00$ & $.90 \leq \mathrm{CFI} \leq .95$ & .955 & Mükemmel Uyum \\
$\mathrm{GFI}$ & $.95 \leq \mathrm{GFI} \leq 1.00$ & $.90 \leq \mathrm{GFI} \leq .95$ & .914 & Kabul Edilebilir Uyum \\
$\mathrm{AGFI}$ & $.90 \leq \mathrm{AGFI} \leq 1.00$ & $.85 \leq \mathrm{AGFI} \leq .90$ & .863 & Kabul Edilebilir Uyum \\
$\mathrm{IFI}$ & $.95 \leq \mathrm{IFI} \leq 1.00$ & $.90 \leq \mathrm{IFI} \leq .95$ & .955 & Mükemmel Uyum \\
\hline
\end{tabular}

*(Kline, 2011)

Tablo 2 incelendiğinde modelin IFI ve CFI değerlerinin mükemmel derecede uyum sağladığı görülmektedir. Diğer uyum indekslerinin de kabul edilebilir düzeyde olması, DFA modelinin veri setiyle uyumlu olduğu şeklinde yorumlanabilir.

\section{Güvenilirlik Çalışmalarına Yönelik Bulgular}

Ölçeğin alt boyutlarında yer alan maddelerin toplam korelasyonları ve alfa iç tutarlılık katsayıları Tablo 3'te verilmiştir.

Tablo 3

iÖEGÖ’nün Alt Boyutlarının Güvenilirlik Analizi Sonuçları

\begin{tabular}{|c|c|c|}
\hline Boyutlar & Maddeler & Alfa \\
\hline 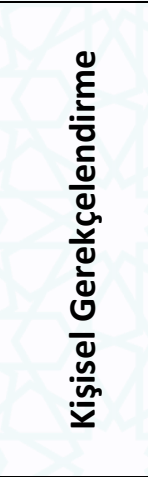 & $\begin{array}{l}\text { 1) İnternette tarihle ilgili herhangi bir konuya dair bir bilgiye ulaştığımda } \\
\text { bu bilginin konu hakkındaki kendi kişisel anlayışımla uyumlu olup } \\
\text { olmadığına bakarım. } \\
\text { 4) Herhangi bir tarih konusuyla ilgili olarak internetten elde ettiğim } \\
\text { bilgilerin güvenilirliğini, o konu hakkında sahip olduğum bilgilerle } \\
\text { karşılaştırarak değerlendiririm. } \\
\text { 7) Tarihle ilgili bir konu hakkında internette bulduğum bilgilerin mantıklı } \\
\text { ve tutarlı olup olmadığını kontrol ederim. } \\
\text { 10) İnternette tarihle ilgili bir konu hakkında okumalar yaparken, ulaştığım } \\
\text { bilgilerin konu hakkında bildiklerimle uyumlu olup olmadığına bakarım. }\end{array}$ & .70 \\
\hline 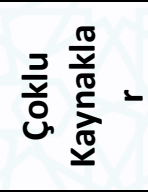 & $\begin{array}{l}\text { 2) Tarihle ilgili bir konu hakkında internette bulduğum ifadeleri, o konuyla } \\
\text { ilgili farklı kaynaklarda yer alan bilgilerle karşılaştırarak değerlendiririm. } \\
\text { 5) Internette tarihe dair okumalar yaparken o konuyu ele alan çeşitli web } \\
\text { sitelerini karşılaştırırım. }\end{array}$ & .83 \\
\hline
\end{tabular}




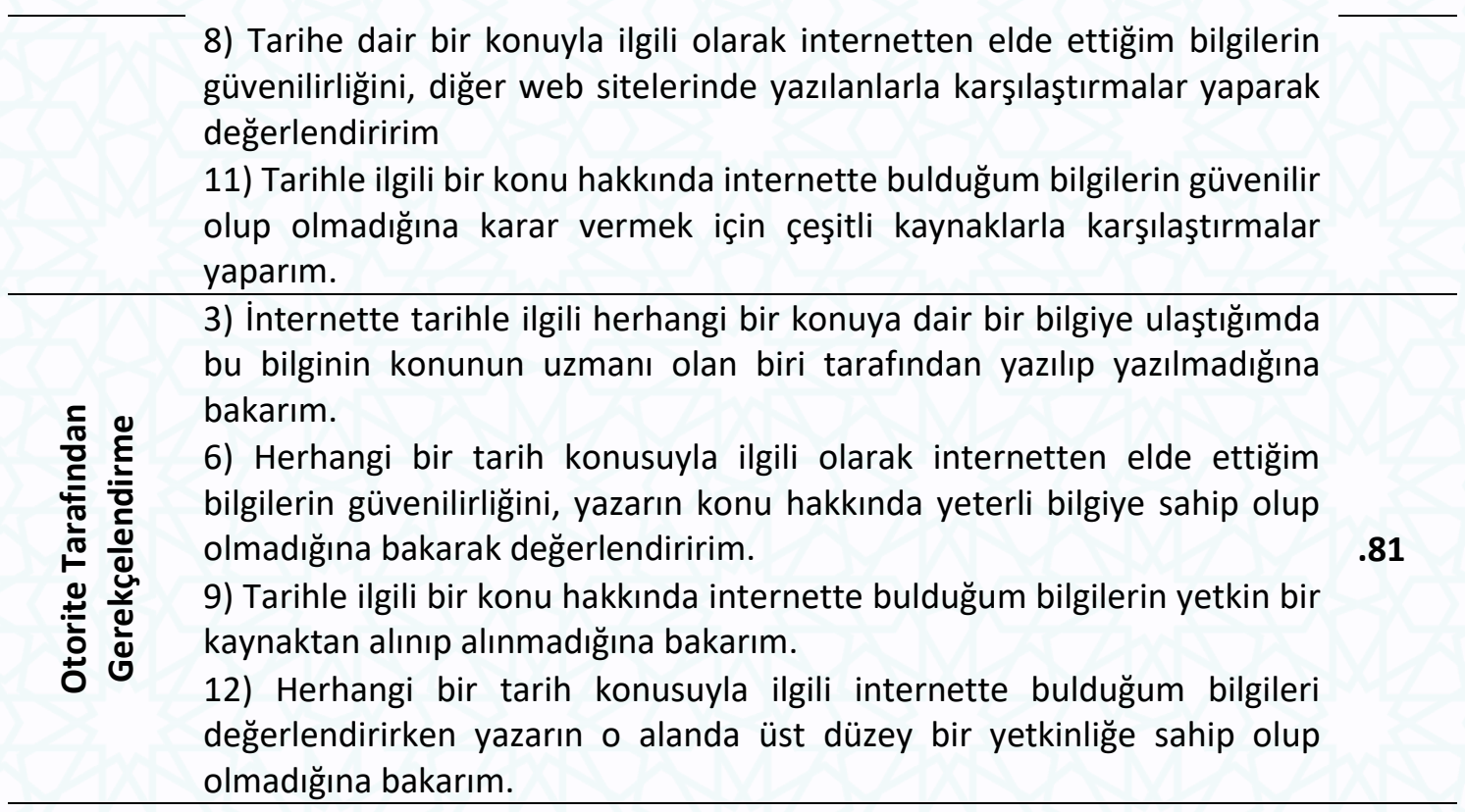

Tablo 3'te görüleceği üzere ölçeğin alt boyutlarının güvenilirlik katsayıları kabul edilebilir düzeydedir. Bu noktadan hareketle internete özgü epistemik gerekçelendirme becerilerini belirlemede ölçeğin güvenilir bir ölçme aracı olduğu söylenebilir. İnternette yer alan bilgi iddialarının gerekçelendirme sürecinde her bir alt boyutun farklı bir gerekçelendirme türünü oluşturması nedeniyle ölçeğin toplam puanları hesaplanmamaktadır. Bu nedenle ölçek genelinin alfa iç tutarlılık güvenilirlik katsayısı hesaplanmamıştır. Ölçeğin alt boyutları arasındaki korelasyon değerleri ve betimsel istatistikler Tablo 4'te verilmiştir.

Tablo 4

Betimsel İstatistikler ve Korelasyon Analizi Sonuçları

\begin{tabular}{lccccc}
\hline Değişken & Ortalama & S & (1) & (2) & (3) \\
\hline Kişisel gerekçelendirme & 4.05 & .75 & 1 & & \\
Çoklu kaynaklar tarafından gerekçelendirme & 4.19 & .77 & $.700^{* *}$ & 1 & \\
Otorite tarafından gerekçelendirme & 4.08 & .82 & $.578^{* *}$ & $.697^{* *}$ & 1 \\
\hline$* *=p<.01$ & & & & &
\end{tabular}
$* *=p<.01$

Tablo 4'te görüleceği üzere ölçeğin alt boyutları arasında .80 'den büyük korelasyon gözlenmemiştir. Bu bulgulardan hareketle her bir alt boyutun birbirinden farklı yapıları temsil ettikleri ve ölçeğin alt boyutları arasında çoklu bağıntı sorunu olmadığı yorumu yapılabilir (Licht, 1995).

\section{Sonuç}

$\mathrm{Bu}$ araştırmada Braten ve diğerleri (2018) tarafından geliştirilen “Internete Özgü Epistemik Gerekçelendirme Ölçeği"nin Türk kültürüne uyarlayarak geçerlik ve güvenirlik çalışmaları yapılmıştır. Araştırma sonuçları "Epistemolojik ve Ontolojik Biliş Modeli” (Greene vd., 2008) kapsamında geliştirilen ölçeğin Türk kültürüne uyumlu olduğunu göstermiştir. 
Geçerlik çalışmaları doğrultusunda yapılan DFA neticesinde 12 madde ve üç alt boyuttan oluşan ölçeğin orijinal yapısının, Türkçe sürümünde de değişmediği ve uyum indekslerinin kabul edilebilir düzeyde olduğu görülmüştür. Güvenilirlik çalışmaları doğrultusunda alt boyutların alfa iç tutarlılık katsayıları yüksek seviyede çıkmıştır. Tüm bu sonuçlar doğrultusunda sosyal bilgiler öğretmen adaylarının internette yer alan tarihsel bilgi iddialarını nasıl ve ne şekilde gerekçelendirdiklerini ortaya koyabilmek için geliştirilen ölçeğin geçerli ve güvenilir olduğunu ortaya koymuştur.

Z kuşağının bireysel öğrenme sürecinde en fazla kullandıkları kaynak internettir. Internet ortamında yer alan bilgilerin kontrol edilemeyecek kadar yoğun bir içeriğe sahip olması ve dileyen herkesin istediği türden içeriği çok rahat bir şekilde erişime sunması gibi nedenler göz önüne alındığında bu bilgi kaynağının dikkatli kullanılması gerektiği aşikardır (Aşkar ve Mazman, 2013). Bu nedenle internette erişilen bilgilerin güvenilirliği, kalitesi, tarafsızlığı ve ilgili konu alanına uygunluğu gibi hususlarda gençlerin doğru karar verebilme becerilerinin geliştirilmesi gerekmektedir (Çelik, 2019; Kammerer, Amann ve Gerjets, 2015). İlgili alanyazın incelendiğinde gençlerin internette eriştikleri kaynakları eleştirel değerlendirebilme becerilerinin zayıf olduğu görülmektedir (Chiu, Tsai ve Liang, 2015; Cho vd., 2018; Tsai, 2009). Gençlerin internette eriştikleri bilgileri nasıl ve ne şekilde yorumladıklarını tespit eden çalışma sonuçları incelendiğinde internete özgü epistemolojik inançların (Braten vd., 2005) önemli bir belirleyici olduğu görülmektedir (Braten vd., 2018; Kammerer vd., 2015; Kammerer, Braten, Gerjets ve Stromso, 2013; Mason, Boldrin ve Ariasi, 2010; Whitmire, 2004).

Kammerer ve diğerleri (2013) tarafından üniversite öğrencileriyle yapılan araştırmada tartışmalı ve belirsiz tıbbi konuların web ortamında araştırıması ile internete özgü epistemolojik inançlar arasındaki ilişkilere bakılmıştır. Bu çalışmada Braten ve diğerleri (2005) tarafından geliştirilen ve gerekçelendirmeyi tek bir boyut olarak ele alan internete özgü epistemolojik inançlar ölçeği kullanılmıştır. Çalışma sonuçları; interneti kesin, net, değişmeyen ve güvenilir bir bilgi kaynağı olarak algılayan öğrencilerin bilgi kaynaklarının güvenilirliği ve türü hakkında daha az geribildirim verdiklerini göstermiştir. Buna ek olarak bu öğrencilerin web aramasında buldukları ilk bilginin kesinliğine daha fazla güvendikleri ve bilgilerin doğruluğunu başka kaynaklardan kontrol etme konusunda isteksiz davrandıkları rapor edilmiştir.

Öte yandan bilginin dinamik, geçici, gelişen, karmaşık ve birbiriyle ilişkili olduğuna yönelik sofistike bir epistemolojik inanç geliştiren bireylerin; bilginin kesin, basit ve değişmez olduğuna yönelik naif bir epistemolojik inanca sahip olanlara kıyasla web ortamında taraflı ve yönlendirici bilgi kaynaklarını ayırt etmede ve bu bilgi kaynaklarına eleştirel yaklaşmada daha başarılı olduğu raporlanmıştır (Çelik, 2019; Mason vd., 2010; Whitmire, 2004). Buna ek olarak “Internete Özgü Epistemolojik İnanç Ölçeği”nin (Braten vd., 2005) kullanıldığı çalışmalarda gerekçelendirme boyutundan yüksek puan alan ve aynı zamanda internette eriştikleri bilgilerin güvenilirliğini diğer kaynaklardan kontrol ederek elde ettikleri sonuçları kendi önceki bilgileriyle karşılaştıran bireylerin; yüksek düzeyde öz-düzenleme becerisine (Chiu, Liang ve Tsai, 2013; Stromso ve Braten, 2010) sahip olmanın yanı sıra web sitelerini daha eleştirel bir gözle (Dong vd., 2015; Knight vd., 2017) inceledikleri vurgulanmıştır. Kammerer ve diğerleri (2015) “internete Özgü Epistemolojik İnanç Ölçeği”nde tek boyut olarak ele alınan gerekçelendirme boyutunu çoklu kaynaklar tarafından gerekçelendirme ve kişisel 
gerekçelendirme adı altında ikiye ayırmışlardır. İlgili araştırma sonuçları; çoklu kaynaklar tarafından gerekçelendirme boyutunu daha çok benimseyen öğrencilerin internette karşılaştıkları çelişkili bilgi iddialarını değerlendirirken konuyu daha iyi anlayabilmek için birden fazla kaynaktan yararlanıp bunları karşılaştırmanın yanı sıra edindikleri bilgilerin doğruluğundan emin olabilmek için web sitelerinde daha fazla zaman geçirdikleri sonucuna ulaşılmıştır. Bunun aksine kişisel gerekçelendirme boyutunu benimseme oranı arttıkça, öğrencilerin güvenilmeyen ticari sitelere daha fazla odaklandıkları sonucuna ulaşılmıştır (Kammerer vd., 2015).

Yukarıda verilen araştırma sonuçları internette karşılaşılan bilgi iddialarını gerekçelendirmede epistemik inançların kilit rol oynadığını ortaya koymaktadır. Bu araştırma sonuçlarından hareketle internete özgü epistemik gerekçelendirme inançları ile tarihsel muhakeme ve tarihsel bağlamsallaştırma becerilerinin tek bir potada eklemleştirilmesi; günümüz bilgi kaynağı olan internetin tarihsel bilginin yapılandırılması sürecinde daha doğru ve yerinde kullanımı açısından önemlidir. Öğrencilerin tarihsel bilgi kaynakları/iddialarını okuyup anlamlandırmak için nasıl ve ne şekilde muhakeme yapabilecekleri konusunda, tarihçilerin kaynağı kanıta dönüştürme sürecindeki uygulamalarını rehber almaları konusunda pek çok tarih eğitimcisi fikir birliğindedir (Cho vd., 2018; Wineburg, 1998). Tarihsel bilgi iddialarının kanıta dönüştürülme sürecinde tarihçiler, pek çok kaynağı birbiriyle karşılaştırarak aralarındaki uyuma odaklanmaktadır. Bu okuma süreci uzmanlık gerektirir. Zira tarihçiler için birden fazla kaynağın olması; farklı bakış açılarını karşılaştırmak ve neden-sonuç bağlantısını kurabilmek için bir fırsattır (Gestsdóttir, van Boxtel ve van Drie, 2018; Monte-Sano, 2011; van Drie ve van Boxtel, 2008). Kaynakların kanıta dönüştürülme sürecinde pek çok farklı kaynağın karşılaştırılarak bir karara varılması, çoklu kaynaklardan tarafından gerekçelendirme boyutu ile benzer niteliktedir. Buna göre mevcut araştırma sonuçlarından hareketle; tarih öğretimi bağlamında internete özgü epistemik gerekçelendirme becerileri ile tarihsel bağlamsallaştırma becerileri arasında anlamlı ilişkiler kurmak için bir çerçeve önerilmiştir. Tarihsel bağlamsallaştırma tarihsel bir olguyu açıklamak, karşılaştırmak, tanımlamak veya değerlendirmek için; tarihsel olayı çevreleyen kronolojik, mekânsal ve toplumsal koşulları bilmek ve o bağlamda bir yargıya ulaşmaktır (Foster ve Yeager, 2001; Huijgen vd., 2014; van Drie ve van Boxtel, 2008). Tarihsel bağlamsallaştırma becerisi tam anlamıyla kazanılmadığı sürece, tarihi fenomenlerin yorumlanması ve tarihi şahsiyetlerin eylemlerinin doğru bir şekilde kavranması çok güçtür (Foster ve Yeager, 2001; Huijgen vd., 2017). Tarihsel bağlamsallaştırma becerisi gelişmemiş öğrencilerin tarihsel olay ve olguları günümüz değer yargılarıyla değerlendirdikleri pek çok ampirik araştırmada rapor edilmiştir (Dinç ve Üztemur, 2018; Hartmann ve Hasselhorn, 2008; Huijgen vd., 2017). İnternet ortamında karşılaştığı tarihsel bilgi iddialarına eleştirel bir bakış açısıyla yaklaşıp doğruluğunu çoklu kaynaklar aracılığıyla kontrol eden öğrenciler büyük ihtimalle tarihsel bağlamsallaştırma becerilerini daha etkin kullanabilecek ve tarihsel bir olayı o zamanın toplumsal, ahlaki ve mekânsal koşullarına uygun olarak değerlendirecektir. Burada önerilen internete özgü epistemik gerekçelendirme inançları ile tarihsel bağlamsallaştırma becerileri arasındaki ilişkilerin daha net ortaya koyulabilmesi için ampirik çalışmalar yapılması gerekmektedir. İleriki çalışmalarda epistemik gerekçelendirme becerilerinin; tarihsel bağlamsallaştırma (Huijgen vd., 2017), tarihsel epistemolojik inançlar (Vansledright ve Reddy, 2014) ve tarihsel bakış açısı edinme becerileri 
(Dinç ve Üztemur, 2018; Hartmann ve Hasselhorn, 2008) ile nasıl ve ne yönde bir ilişki içerisinde olduğunu belirten çalışmalar yapılabilir.

Bu araştırma tarih öğretimi bağlamında internette karşılaştırılan bilgi iddialarının nasıl gerekçelendirildiği üzerine yürütülmüştür. Ölçek farklı konu alanları ve disiplinler üzerinde uyarlanabilmektedir. İnternete özgü epistemik gerekçelendirme davranışlarının Türk kültüründeki yansımalarını geniş bir yelpazede ele alabilmek için ölçeğin farklı̈öneklemler ve konu alanlarında uygulanarak sonuçların karşılaştırılması epistemik gerekçelendirmenin konu alanına özgünlüğünü ortaya koyması açısından önemlidir.

\section{Kaynakça}

Aşkar, P., \& Mazman, S. G. (2013). Adaptation of online information searching strategy inventory into Turkish. Education and Science, 38(168), 167-182.

Brandmo, C., \& Braten, I. (2018). Investigating relations between beliefs about justification for knowing, interest, and knowledge across two socio-scientific topics. Learning and Individual Differences, 62, 89-97. https://doi.org/10.1016/i.lindif.2018.01.010

Bråten, I., Strøms $\varnothing$, H. I., \& Samuelstuen, M. S. (2008). Are sophisticated students always better? The role of topic-specific personal epistemology in the understanding of multiple expository texts. Contemporary Educational Psychology, 33(4), 814-840.

Braten, I., Ferguson, L. E., Strøms $\varnothing$, H. I., \& Anmarkrud, $\varnothing$. (2013). Justification beliefs and multiple-documents comprehension. European Journal of Psychology of Education, 28, 879-902. https://doi.org/10.1007/s10212-012-0145-2

Braten, I., Ferguson, L. E., Strøms $\varnothing$, H. I., \& Anmarkrud, $\varnothing$. (2014). Students working with multiple conflicting documents on a scientific issue: Relations between epistemic cognition while reading and sourcing and argumentation in essays. British Journal of Educational Psychology, 84, 58-85. doi:10.1111/bjep.12005

Bråten, I., Brandmo, C., \& Kammerer, Y. (2019). A validation study of the internet-specific epistemic justification inventory with Norwegian preservice teachers. Journal of Educational Computing Research, 57(4), 877-900.

Braten, I., Strøms $\varnothing$, H. I., \& Samuelstuen, M. S. (2005). The relationship between Internetspecific epistemological beliefs and learning within Internet technologies. Journal of Educational Computing Research, 33, 141-171.

Chinn, C.A., Buckland, L.A., and Samarapungavan, A. (2011). Expanding the dimensions of epistemic cognition: Arguments from philosophy and psychology. Educational Psychologist, 46, 141-167. https://doi.org/10.1080/00461520.2011.587722

Chiu, Y.L., Liang, J.C., \& Tsai, C.C. (2013). Internet-specific beliefs and self-regulated learning in online academic information searching. Metacognition and Learning, 8, 235-260. https://doi.org/10.1007/s11409-013-9103-x 
Chiu, Y. L., Tsai, C. C., \& Liang, J. C. (2015). Testing measurement invariance and latent mean differences across gender groups in college students' Internet-specific epistemic beliefs. Australasian Journal of Educational Technology, 31(4), 486-499.

Cho, B. Y., Han, H., \& Kucan, L. L. (2018). An exploratory study of middle-school learners' historical reading in an internet environment. Reading and Writing, 31(7), 1525-1549.

Çokluk, Ö., Şekercioğlu, G. \& Büyüköztürk, Ş. (2014). Çok değişkenli istatistik SPSS ve LISREL uygulamaları. (3. baskı). Ankara: Pegem.

Dinç, E. ve Üztemur, S. (2019). Ortaokul öğrencileri ve öğretmenlerinin bilginin gerekçelendirilmesi sürecinde benimsedikleri epistemik inançlarının karşılaştırmalı nitel analizi. Cumhuriyet International Journal of Education, 8(2), 361-405. http://dx.doi.org/10.30703/cije.471871

Dinç, E. ve Üztemur, S. (2018). Tarihsel bakış açısı edinme ölçeğinin Türkçeye uyarlanması ve tarih ve sosyal bilgiler öğretmen adaylarının tarihsel bakış açısı edinme becerilerinin incelenmesi. Anadolu Journal of Educational Sciences International, 8(2), 478-518. DOI: 10.18039/ajesi.454643

Doğan, N., Soysal, S., \& Karaman, H. (2017). Aynı örnekleme açımlayıcı ve doğrulayıcı faktör analizi uygulanabilir mi? Ö. Demirel ve S. Dinçer (edt). Küreselleşen dünyada eğitim. (373-400). Ankara: Pegem.

Dong, Y., Liang, J. C., Yu, Y. Y., Wu, J. C., \& Tsai, C. C. (2015). The relationships between Chinese higher education students' epistemic beliefs and their judgmental standards of searching for literature online: Undergraduate versus graduate comparisons. Interactive Learning Environments, 23(2), 250-266.

Ferguson, L. E., \& Bråten, I. (2013). Student profiles of knowledge and epistemic beliefs: Changes and relations to multiple-text comprehension. Learning and Instruction, 25, 49-61.

Ferguson, L. E., Braten, I., \& Strøms $\varnothing$, H. I. (2012). Epistemic cognition when students read multiple documents containing conflicting scientific evidence: A think-aloud study. Learning and Instruction, 22, 103-120

Ferguson, L. E., Bråten, I., Strøms $\varnothing$, H. I., \& Anmarkrud, $\varnothing$. (2013). Epistemic beliefs and comprehension in the context of reading multiple documents: Examining the role of conflict. International Journal of Educational Research, 62, 100-114. https://doi.org/10.1016/i.ijer.2013.07.001

Foster, S., \& Yeager, E. A. (2001). The role of empathy in the development of historical understanding. O. L. Davis, E. A. Yeager, \& S. Foster (Eds.). Historical empathy and perspective taking in the social studies (pp. 13-21). Oxford: Rowman and Littlefield.

Fraenkel, J. R., Wallen, N. E., \& Hyun, H. H. (2012). How to design and evaluate research in education. (8th edt). New York: McGraw-Hill Humanities/Social Sciences/Languages. 
Gestsdóttir, S. M., van Boxtel, C., \& van Drie, J. (2018). Teaching historical thinking and reasoning: Construction of an observation instrument. British Educational Research Journal, 44(6), 960-981.

Greene, J.A., Azevedo, R., and Torney-Purta, J. (2008). Modeling epistemic and ontological cognition: Philosophical perspectives and methodological directions. Educational Psychologist, 43, 142-160. https://doi.org/10.1080/00461520802178458

Greene, J.A., Torney-Purta, J., and Azevedo, R. (2010). Empirical evidence regarding relations among a model of epistemic and ontological cognition, academic performance, and educational level. Journal of Educational Psychology, 102, 234-255 http://psycnet.apa.org/doi/10.1037/a0017998

Hartmann, U., \& Hasselhorn, M. (2008). Historical perspective taking: A standardized measure for an aspect of students' historical thinking. Learning and Individual Differences, 18(2), 264-270.

Hofer, B. K. (2004). Exploring the dimensions of personal epistemology in differing classroom contexts: Student interpretations during the first year of college. Contemporary Educational Psychology, 29(2), 129-163.

Hofer, B. K. (2006). Domain specificity of personal epistemology: Resolved questions, persistent issues, new models. International Journal of Educational Research, 45(1-2), 85-95.

Hofer, B. and Pintrich, P. R. (1997). The development of epistemological theories: Beliefs about knowledge and knowing and their relation to learning. Review of Educational Research, 67(1), 88-144. https://doi.org/10.3102/00346543067001088

Huijgen, T., Van Boxtel, C., Van de Grift, W., \& Holthuis, P. (2017). Toward historical perspective taking: Students' reasoning when contextualizing the actions of people in the Past. Theory \& Research in Social Education, 45, 110-144.

Huijgen, T., Grift, W., van Boxtel, C., \& Holthuis, P. (2018): Promoting historical contextualization: the development and testing of a pedagogy. Journal of Curriculum Studies. Doi: 10.1080/00220272.2018.1435724

Huijgen, T., Van Boxtel, C., Van de Grift, W., \& Holthuis, P. (2014). Testing elementary and secondary school students' ability to perform historical perspective taking: The constructing of valid and reliable measure instruments. European Journal of Psychology of Education, 29, 653-672. doi:10.1007/s10212-014-0219-4

Kammerer, Y., Amann, D. G., \& Gerjets, P. (2015). When adults without university education search the Internet for health information: The roles of Internet-specific epistemic beliefs and a source evaluation intervention. Computers in Human Behavior, 48, 297309.

Kammerer, Y., Braten, I., Gerjets, P., \& Stromso, H. I. (2013). The role of Internet specific epistemic beliefs in laypersons' source evaluations and decisions during Web search on a medical issue. Computers in Human Behavior, 29(3), 1193-1203. 
Kline, R. B. (2011). Principles and practice of structural equation modeling. (3. Edition). New York/London: The Guilford.

Knight, S., Rienties, B., Littleton, K., Mitsui, M., Tempelaar, D., \& Shah, C. (2017). The relationship of (perceived) epistemic cognition to interaction with resources on the internet. Computers in Human Behavior, 73, 507-518.

Köymen, B., Rosenbaum, L. \& Tomasello, M. (2014). Reasoning during joint decisionmaking by preschool peers. Cognitive Development, 32, 74-85.

Kuhn, D., Cheney, R. \& Weinstock, M. (2000). The development of epistemological understanding. Cognitive Development, 15(3), 309-328.

Lee, R., Looi, K. H., Khan, H., Soong, H., \& Neale, L. (2019). Measuring students' justificatory reasoning approaches. Issues in Educational Research, 29(3), 807.

Licht, M. H. (1995). Multiple regression and correlation. I. L. G. Grimm \& P. R. Yarnold (Eds.), Reading and understanding multivariate statistics. Washington, DC: American Psychological Association.

Monte-Sano, C. (2011). Beyond reading comprehension and summary: Learning to read and write in history by focusing on evidence, perspective, and interpretation. Curriculum Inquiry, 41(2), 212-249.

Mason, L., Boldrin, A., \& Ariasi, N. (2010). Searching the Web to learn about a controversial topic: Are students epistemically active? Instructional Science, 38(6), 607-633.

Nagel, J. (2015). The social value of reasoning in epistemic justification. Episteme, 12(2), 297308. https://doi.org/10.1017/epi.2015.4

Pearcy, M. (2014). Student, teacher, professor: Three perspectives on online education. The History Teacher, 47 (2), 169-185.

Schommer, M. (1990). Effects of beliefs about the nature of knowledge on comprehension. Journal of Educational Psychology, 82(3), 498-504.

Soong, H., Lee, R. \& John, G. (2012). Cultural differences in justificatory reasoning. Educational Review, 64(1), 57-76. https://doi.org/10.1080/00131911.2011.571764

Strøms $\varnothing$, H. I., \& Bra ${ }^{\circ}$ ten, I. (2010). The role of personal epistemology in self-regulation of Internet-based learning. Metacognition and Learning, 5, 91-111.

Şimşek, A. ve Yalı, S. (2019). Gerçekte(n) öyle mi olmuş: post truth zamanlarda tarihin temsili. İstanbul: Yeni insan.

Tavşancıl, E. (2019). Tutumların ölçülmesi ve SPSS ile veri analizi. (6. Baskı). Ankara: Nobel.

Tezbaşaran, A. (2008). Likert tipi ölçek hazırlama kılavuzu. Üçüncü Sürüm e-Kitap. Türk Psikologlar Derneği.

Trochim, W.M. \& Donnelly, J. P. (2006). The research methods knowledge base (3. bs.). Cincinnati, $\mathrm{OH}$ : Atomic Dog. 
Tsai, M.J. (2009). Online information searching strategy inventory (OISSI): A quick version and a complete version. Computers \& Education 53. 473-483.

Vansledright, B., \& Reddy, K. (2014). Changing epistemic beliefs? An exploratory study of cognition among prospective history teachers. Revista Tempo e Argumento, Florianópolis, v. 6, n.11, p. 28-68, jan./abr. 2014. http://dx.doi.org/10.5965/2175180306112014028

van Drie, J., \& van Boxtel, C. (2008). Historical reasoning: Towards a framework for analyzing students' reasoning about the past. Educational Psychology Review, 20(2), 87-110.

Wineburg, S. (1991). Historical problem solving: A study of the cognitive processes used in the evaluation of documentary and pictorial evidence. Journal of Educational Psychology, 83(1), 73-87.

Wineburg, S. (1998). Reading Abraham Lincoln: An expert/expert study in the interpretation of historical texts. Cognitive Science, 22(3), 319-346.

Whitmire, E. (2004). The relationship between undergraduates' epistemological beliefs, reflective judgment, and their information-seeking behavior. Information Processing \& Management, 40(1), 97-111. 